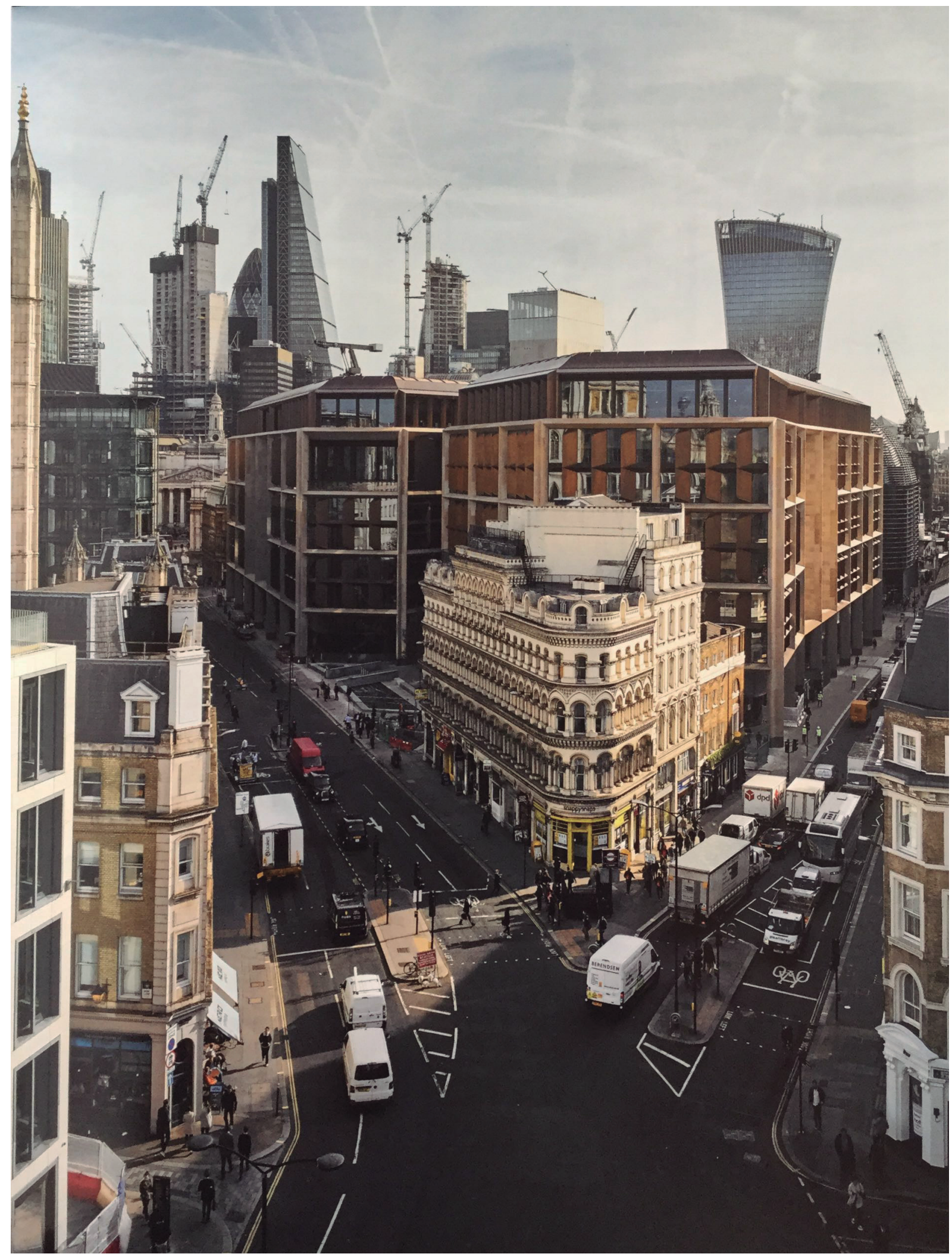




\section{Browsing. De la exploración a la navegación, o la mutación del (no) proyecto de arquitectura Juan Coll-Barreu}

El artículo observa el germen del proyecto de arquitectura, la vieja "autoría", y lo confronta con el proceso contemporáneo en el que la acumulación hiperpublicitada de recursos es utilizada para la incesante reproducción del entorno construido. El texto demuestra que la actual pluralidad de lo preexistente se implica radicalmente en la producción de nuevos "contenidos" mediante su intromisión en la máquina del arquitecto. El autor del artículo analiza desde esa óptica dos proyectos recientes de arquitectura, de respetada autoría, para identificar una aparente renuncia al proyecto y a la autoría en beneficio de lo que denomina browsing e identifica con el impulsivo scroll down de la navegación en la red.

\section{PALABRAS CLAVE}

Visiones, browsing, arquitectura, producción, cultura, ciudad, oportunidad, Norman Foster, Peter Zumthor

\section{KEYWORDS}

Visions, Browsing, Architecture, Production, Culture, City, Opportunity, Norman Foster, Peter Zumthor

\section{S. XXI, ARQUITECTURA Y PLURIAUTORÍA}

La reflexión sobre la autoría en la arquitectura ha construido durante las primeras décadas del siglo una constelación de acercamientos a la pluralidad de los agentes productores de diseño, los tiempos implicados y los usuarios favorecidos por las actuaciones de los arquitectos, o al papel de estos como cohesionadores de actividades, sociedades, grupos y geografías diversos, cuando no opuestos. Coincidentemente se han organizado alrededor del concepto de coexistencia, una expresión que evita referirse a la producción de los hechos o las relaciones y pospone

\begin{abstract}
Juan Coll-Barreu
es doctor arquitecto, profesor de proyectos arquitectónicos en la Escuela de Arquitectura de Madrid ETSAM Universidad Politécnica de Madrid UPM, en donde dirige la Unidad Docente CollBarreu, el curso internacional "Madrid Intercultural" y estudios de doctorado, visiting professor en NC State University School of Architecture en los EEUU y director del estudio COLL-BARREU ARQUITECTOS con sedes en Madrid y Bilbao. Su obra construida ha sido internacionalmente publicada y premiada, así como expuesta en algunas de las salas de arquitectura más importantes del mundo, como el Skyscraper Museum de Nueva York. Es autor de numerosas libros monográficos, capítulos de libros y artículos científicos en revistas indexadas, $y$ frecuente conferenciante y ponente en instituciones nacionales e internacionales. E-mail: j.coll.barreu@upm.es ORCID iD: 0000-0002-7706-6556 Researcher ID: AAU 67472020
\end{abstract}

Fig. 01

Foster + Partners, sede de Bloomberg, Londres, 2017. Vista general exterior desde la confluencia de Queen Victoria St. y Cannon St. Foto James Newton. 
en la práctica la observación directa del problema de la autoría, como si ese estadio se hubiera decretado provisionalmente inexistente. Son ejemplos de esto el proyecto "Landscapes of Coexistence"1 presentado en Future Architecture en 2018, más tangencialmente el congreso "Architecture of Coexistence"2 desarrollado en Guadalajara, México, también en 2018 y, de modo muy revelador, el trabajo "The Architecture of Coexistence..." relato arquitectónico que unió nada menos que a sunitas y chiíes en una consciente simbiosis edilicia durante la Edad Media.

Sin embargo, esa misma idea que parece universalmente asumida no se ha trasladado al aspecto nuclear de la arquitectura, al interior del proyecto. Es evidente el consenso científico que celebra la "coexistencia" como mónada de la arquitectura contemporánea, pero no comprobar su presencia activa en la "autoría" del proyecto deja en suspenso su plena validez. Este texto intentará observar precisamente ese proceso germinal y comprobará que el contenido global y la acumulación hiperpublicitada de recursos son utilizados para la incesante reproducción del entorno construido. De ser así, no cabría una implicación más radical de la pluralidad preexistente que su "intromisión" en la máquina del autor. Hace ya cuatro años los conocimientos sobre la evolución de las especies se completaron de una forma realmente cautivadora, después de que los estudios de Roberto Cazzola Gatti ${ }^{4}$ confirmados empíricamente por David A. Marques ${ }^{5}$ dibujaran una multiplicidad tridimensional de pluriautorías. En ella, la simplista lucha darwiniana por la supervivencia como explicación del mecanismo de avance biológico es reemplazada por una acumulación de relaciones acomodaticias o simplemente por la "simpatía real" como instrumento que facilita no sólo la convivencia sino también la aparición de nuevas especies. Este vuelco en la teoría de la evolución parece poseer una lógica irrebatible cuando lo observamos a la luz de la hiperconectividad de la segunda década del siglo XXI y sitúa la idea de multiplicidad productora basada en previas producciones ya existentes nada menos que en la explicación de nuestra propia naturaleza transformativa.

En este nuevo entendimiento del modo de producirnos y nuevo modo de producir la arquitectura, el espray sustituye a la línea y a sus ramificaciones, la navegación a la exploración y, lo que es probablemente más significativo, el desinterés -entendiéndose este como falta de ascendiente, de predominio- al itinerario.

EXPLORACIÓN

"Recherches", "Búsquedas", era el atinado plural con que Le Corbusier y Ozenfant titularon, en 1924, el artículo publicado en el número 22 de la revista L'Esprit Nouveau (fig. 02) en el que, antes de repasar los éxitos plásticos de las sucesivas exploraciones personales que desembocarían en la aparición del cubismo, cada una de las cuales avanzaba significativamente sobre el estadio anterior, definían "búsqueda" refiriéndose al "hecho" buscado y a la eficacia de la indagación, como "el choque, a veces brutal, de unas ideas nuevas que aportan hechos nuevos que trastocan las costumbres". Estos "hechos nuevos", continuaban, "aportan medios sólidos a las nuevas generaciones"7. La "novedad" proporcionaba la "solidez", en ocasiones implantada con "brutalidad", y el artista -el pintor, el arquitectoera el descubridor, el explorador de lo "nuevo". "Búsqueda" fue también el término utilizado por Frank Lloyd Wright, otro gran explorador en la misma 


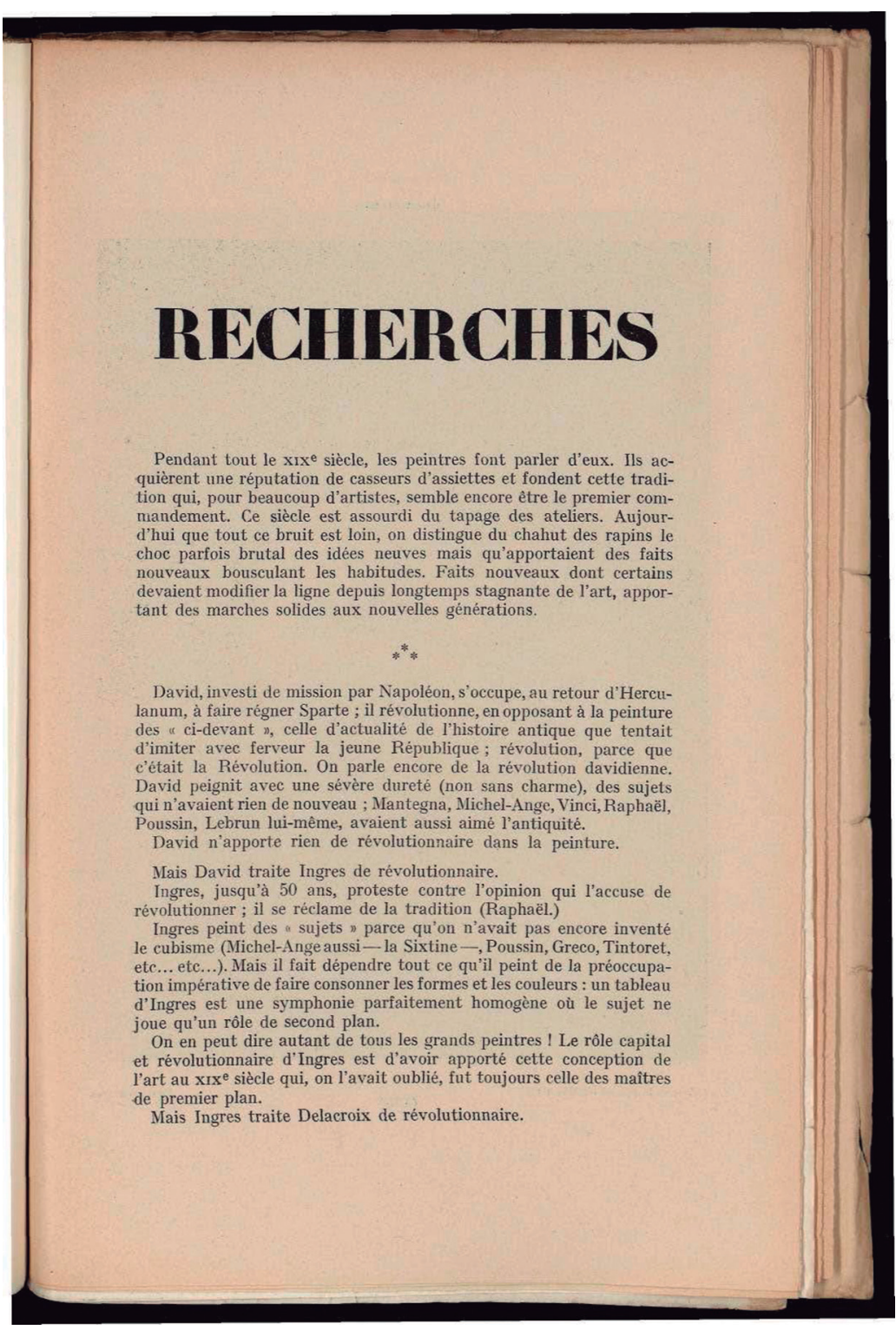

02

década de los años 20 al otro lado del Atlántico. "He estado buscando el ideal de la vida y buscando simultáneamente la construcción ideal"8 había proclamado entonces el maestro de las praderas, quien en 1943 retomó sus escritos autobiográficos con un anuncio que no dejaba dudas sobre la permanencia de su misión: "la temprana búsqueda de la forma continúa".

La postura coincidente de los antagónicos Le Corbusier y Wright no difería sustancialmente de la sostenida por el resto de los grandes arquitectos de la vanguardia moderna, según la expresaron en manifiestos, libros y conferencias. La "búsqueda" era, para ellos, la sucesión de descubrimientos basados en un permanente esfuerzo personal que convertían al arquitecto en un investigador, un explorador de lugares que antes no habían existido, de caminos liberadores que, por encima de todo, debían poseer la cualidad de intransitados, inexplorados.
Fig. 02

Amédée Ozenfant y Le Corbusier, primera página del artículo "Recherches" en el número 22 de L’Esprit Nouveau, París, 1924. 


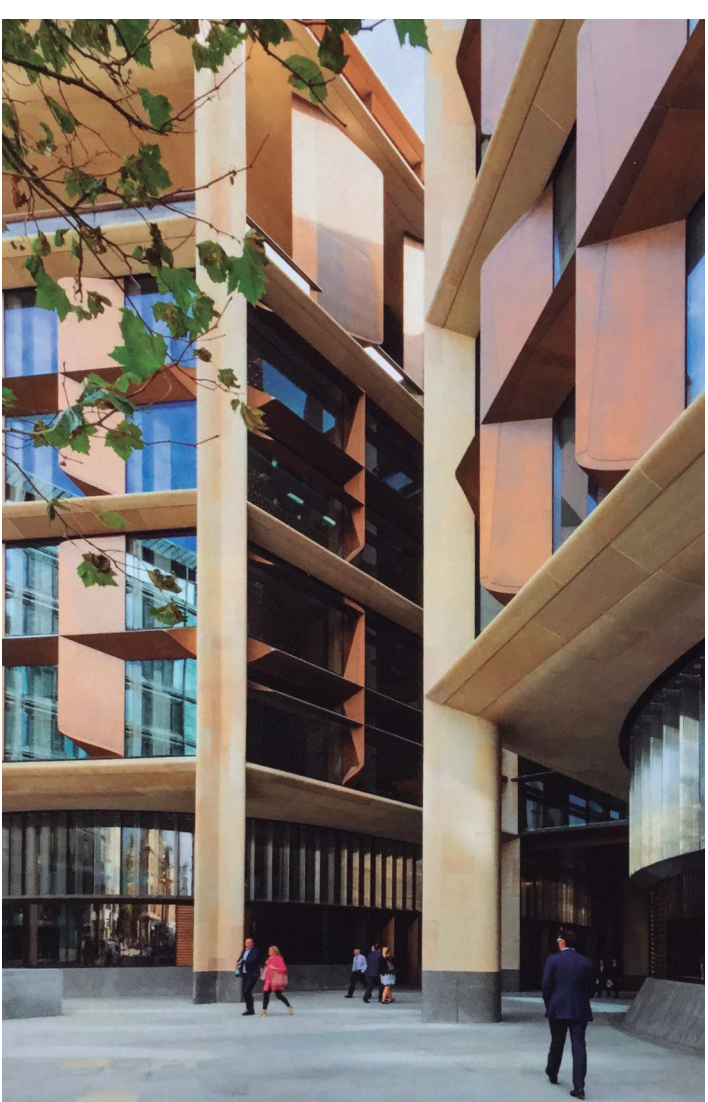

03

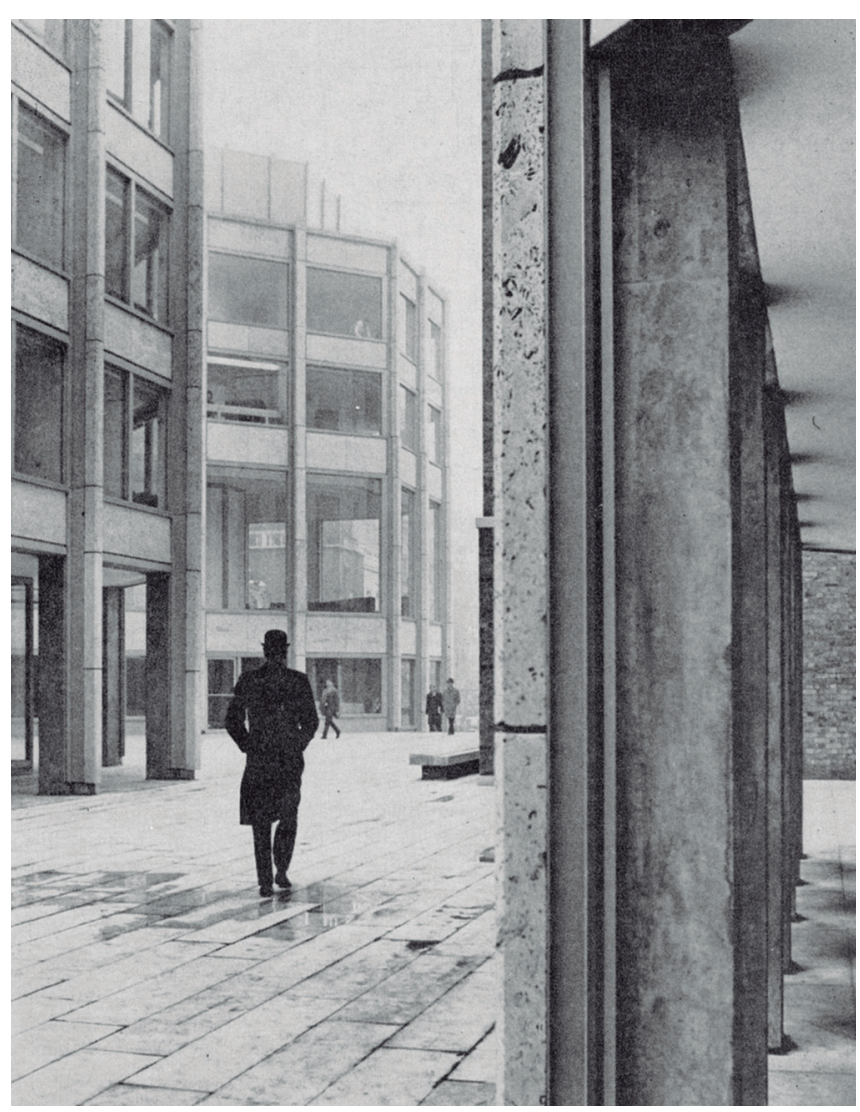

04

Esta imperturbable convicción a propósito de la investigación, de la exploración como motor del progreso, construyó literalmente el siglo XX y ha continuado en las dos primeras décadas del siglo XXI como un implícito marco intelectual en el que se inscribe tanto el pensamiento sobre arquitectura como la crítica de las obras.

SCROLLING DOWN

Sin embargo, el trabajo de un arquitecto hoy se aleja de la exploración propia del milenio pasado y se acerca sin vacilaciones al browsing o navegación en la red inherente al milenio actual y más todavía al (aparente) aislamiento pandémico producido por la covid-19. Ahora, hacer arquitectura no es una búsqueda sino una navegación sobre un mar cada vez más extenso formado por territorios todos explorados, mil veces navegados y visitados. La analogía actual de la acción de proyectar no es el atractivo personaje del explorador que se adentraba en territorios ignotos que ya no existen, sino el ansia convulsiva $-y$, aún más que cotidiana, permanente- del scroll down.

Tomemos dos ejemplos recientes, aclamados unánimemente por la crítica internacional en su todavía corta vida publicada, y terminados por sendos arquitectos europeos cuyas carreras anteriores no son susceptibles de ser consideradas ajenas a la exploración de nuevos territorios para la modernidad. 
El primero es la nueva sede para Bloomberg en Londres construida por Norman Foster ${ }^{10}$ en 2017 (fig. 01). Se sitúa a escasos pasos del icónico -y explorador- 30 Saint Mary Axe terminado por el mismo arquitecto en 2004, y un buen ejemplo de la linealidad metodológica de su carrera. Trece años después, el edificio cuestiona la construcción vertical como solución recuperada en las últimas décadas para la implantación de sedes corporativas en los centros urbanos, muy especialmente en la City de Londres. Parece que fuera la primera advertencia sobre un tipo edificatorio que la pandemia de 2020 y su subsiguiente cuarentena global y adaptación al teletrabajo han dejado herido de gravedad. A cambio de la altura, la central británica del gigante de la comunicación se organiza en prismas irregulares de nueve plantas aparentes, totalmente de vidrio pero revestidas con enormes pilastras, molduras, cornisas y lamas de bronce y piedra caliza, que le permiten relacionarse con el suntuoso lenguaje clásico de los edificios que lo rodean y con el pasado bimilenario de uno de los enclaves más antiguos de la ciudad.

Sin embargo, la mayor transformación provocada por el edificio Bloomberg sobre la aludida linealidad del discurso inventivo de Foster, que ejemplificábamos en el geográficamente cercano "The Gherkin", no son sus decisiones proyectivas sino precisamente el modo en que estas se encuentran y aplican. La cadena de exploraciones de las épocas anteriores deja paso ahora a una brillante selección y aplicación simultánea de imágenes, estrategias y significados. Foster navegante sustituye a Foster descubridor. La dispersión del programa en volúmenes, el plano de piedra sobre el que se levantan y la elegante ortogonalidad de sus fachadas, chaflanes incluidos, son los planteamientos urbanos del complejo del Economist construido en 1964 por Alison y Peter Smithson en la misma (figs. 03, 04) ciudad de Londres. El bronce que envuelve el edificio y su insistencia matérica estaba todavía más cerca, en el prisma del mismo material que Mies van der Rohe proyectó en 1967 y nunca ejecutó casi en el mismo solar, al otro lado de Queen Victoria Street". Las pasarelas curvas y entrelazadas del interior nacieron en la piscina para pingüinos del Zoológico de Londres construida por Berthold Lubetkin (figs. 05, 06) en 1934. El arquitecto navega también por su propia obra, y el edificio de Willis, Faber y Dumas de 1975 en Ipswitch aporta la compacidad urbana y de baja altura de un edificio corporativo en donde a las oficinas se añaden usos lúdicos y de descanso, es atravesado por un eje peatonal, posee una dinámica ascendente y una planta de proporciones muy similares.

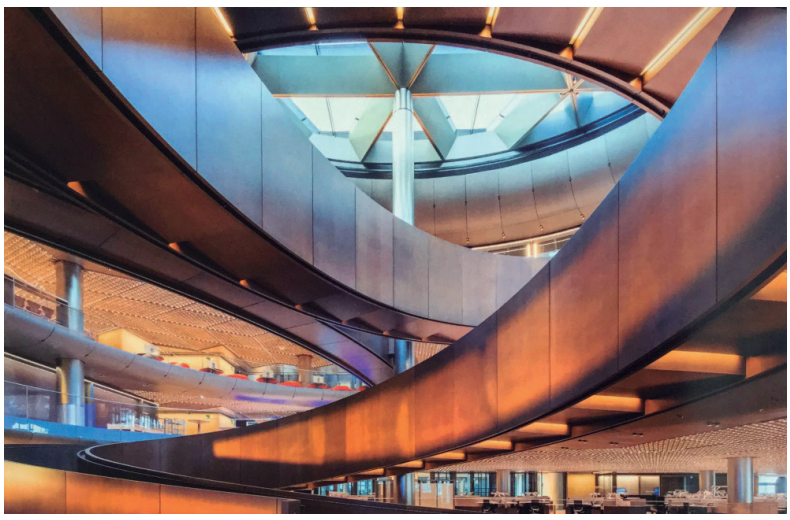

05
Fig. 03

Foster + Partners, sede de Bloomberg, Londres, 2017. Uno de los accesos desde Queen Victoria St. Foto Nigel Young / Foster + Partners.

Fig. 04

Alison y Peter Smithson, conjunto de edificios Economist, Londres, 1964. Foto Michael Carapetian.

Fig. 05

Foster + Partners, sede de Bloomberg, Londres, 2017. Rampa interior. Foto Nigel Young / Foster + Partners.

Fig. 06

Berthold Lubetkin, piscina para pingüinos en el Zoológico de Londres, 1934.

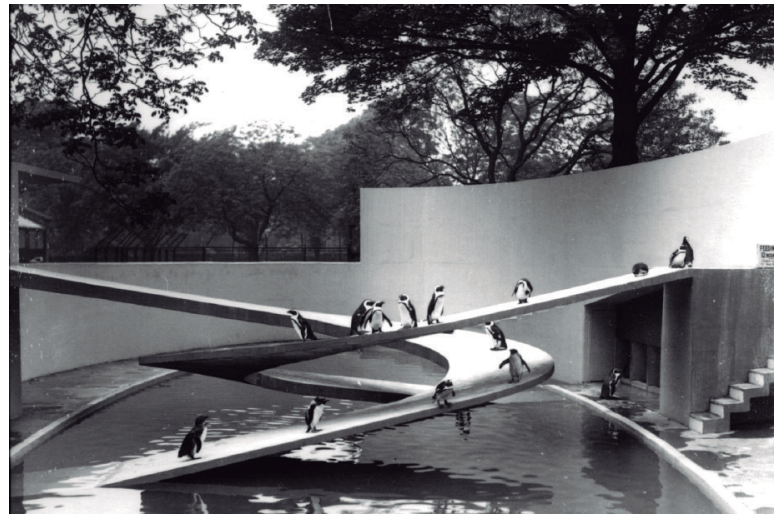

06 


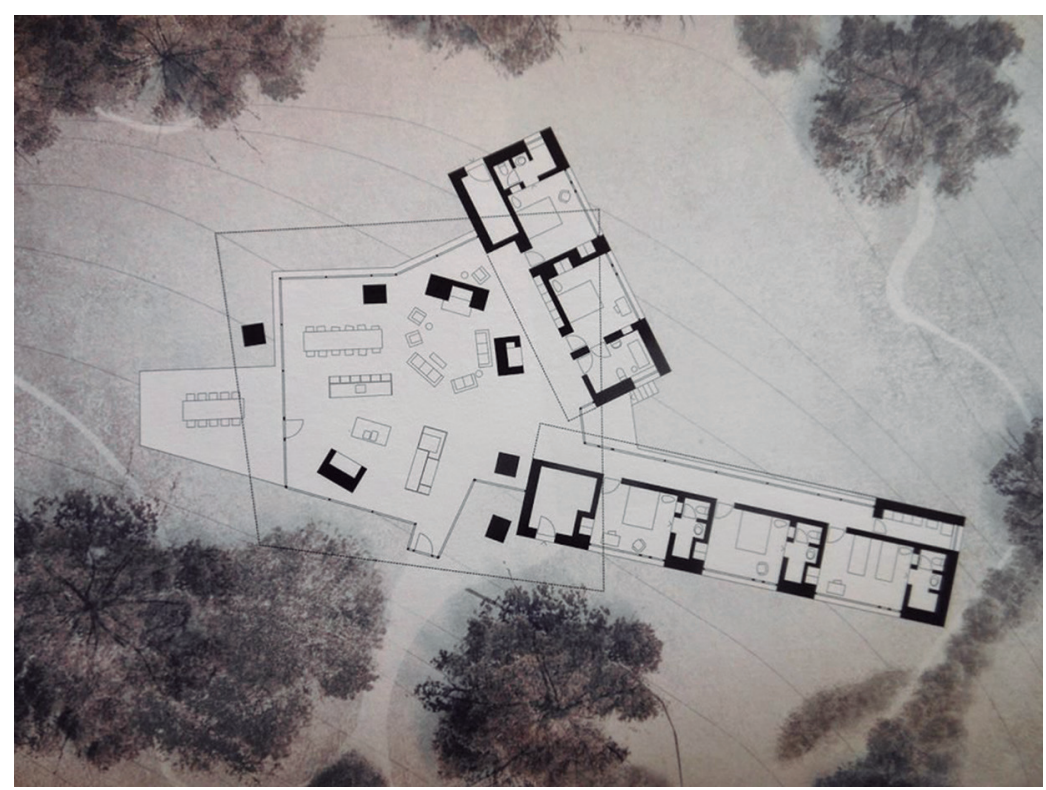

07

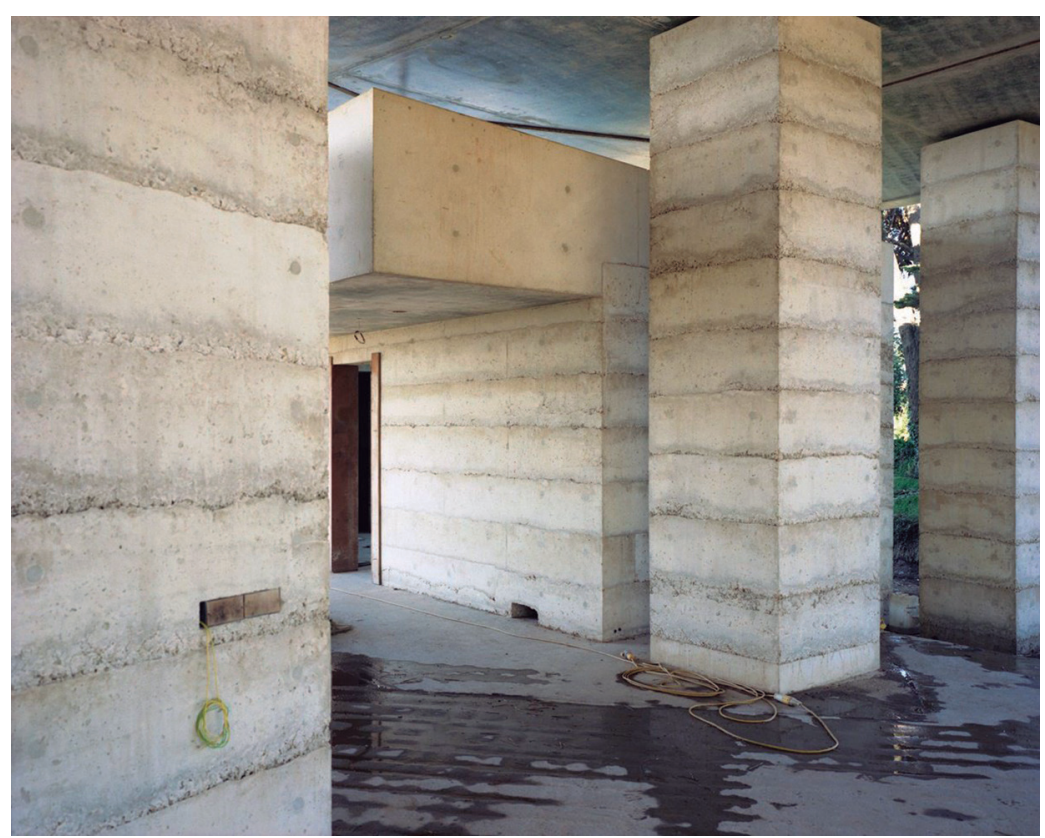

08

El segundo ejemplo es de una escala mucho más modesta, pero parecería también un anticipo de los nuevos ideales pospandémicos, en este caso el contacto con la naturaleza, la vida recluida fuera de la ciudad y la hipertecnificación de ese aislamiento. La villa en Devon de Peter Zumthor ${ }^{12}$ es su primera obra permanente en el Reino Unido ${ }^{13}$ y la componen un racimo de piezas de hormigón y vidrio (fig. 07) abiertas a la contemplación del paisaje ondulado, húmedo y cálido del Sur de Inglaterra.

El encargo finalizado en 2018 por el arquitecto suizo ha navegado (tanto en su forma terminada como en sus maquetas y documentos de trabajo) por los dólmenes (fig. 08) prehistóricos -vueltos a 


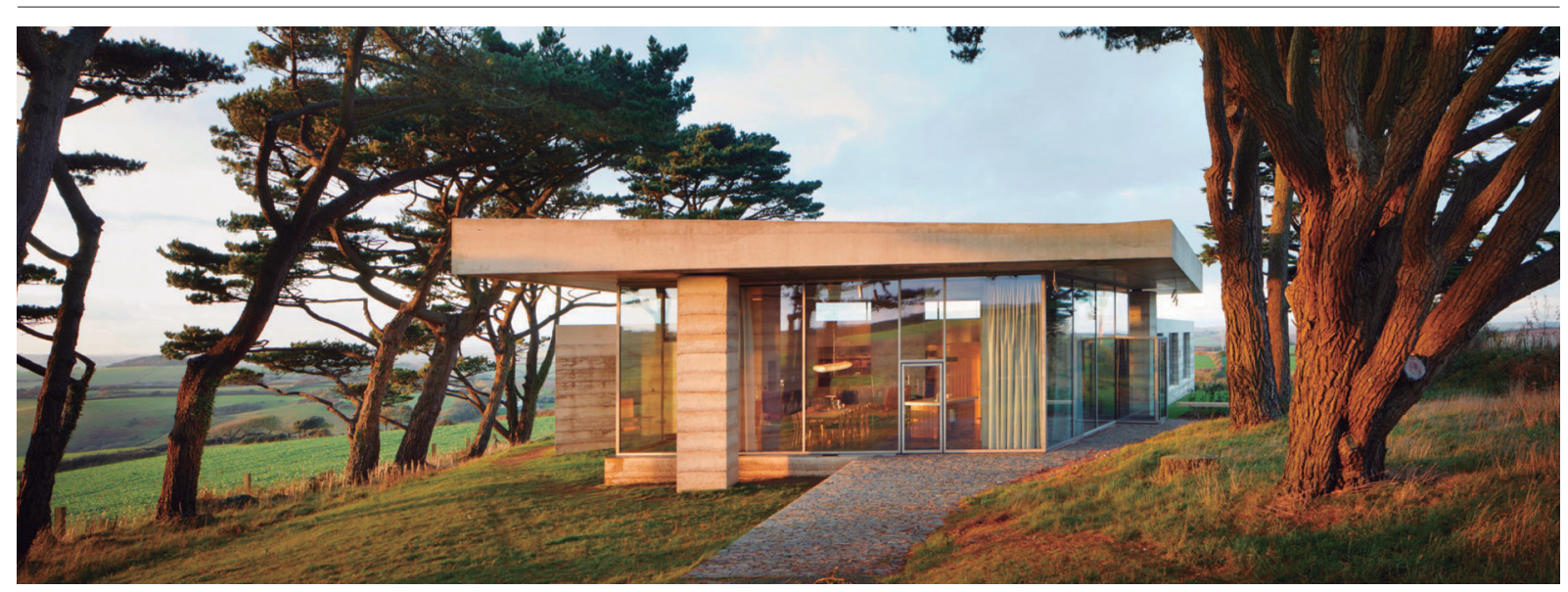

09

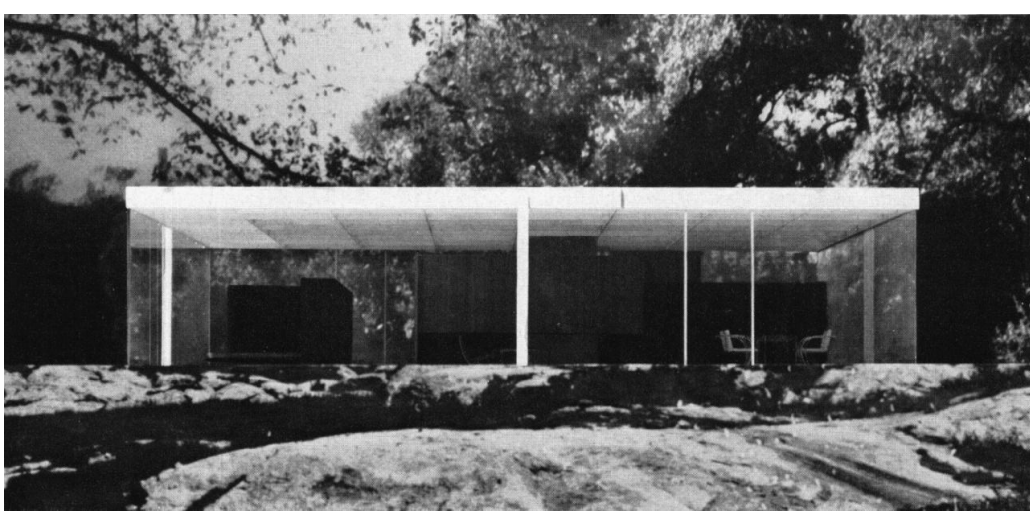

10

utilizar después, entre otros, por Superflex en "Dive-In", su instalación rosa en el globalizado desierto de Coachella-; los hormigones forzosamente artesanales de Le Corbusier en Chandigarh tal como todavía se observan en los pies derechos del edificio del Secretariado; también por Mies van der Rohe, esta vez por su casa 50 por 50 -de 1950, como debía ser en el maestro de la perfección- cuya planta cuadrada de vidrio con cuatro accesos situados en esvástica, ocupada como un espacio continuo gracias a la disposición de piezas interiores exentas, es exactamente (figs. 09, 10) la planta de la casa en Devon; o, como en el ejemplo de Foster, por la propia obra del arquitecto, también revisitada aquí, donde la fachada al paisaje de las termas de Vals cambia de escala con fidelidad milimétrica para transformarse en los alzados de los dormitorios (figs. 11, 12) de esta casa inglesa.

Existe un precedente arcaico, es decir, anterior a los tiempos de las redes sociales, de este sistema plurirreferente para hacer arquitectura. Lo encontramos en la agrupación de tiempos y lugares vividos por Marna y Rockwell Schnabel con que Frank O. Gehry compuso en 1990 la casa de la pareja en Brentwood, Los Ángeles. El arquitecto invitó a los clientes a rememorar "cosas significativas, ideas que os hayan gustado, lugares que os hayan gustado, retazos o piezas de vuestra vida que os gustaría recordar"14 para componer el collage arquitectónico de la vivienda, si bien allí cada categoría aludida era correspondida por una pieza diferente, y las llamadas todavía no se entremezclaban para configurar la arquitectura.
Fig. 07

Peter Zumthor, villa en Devon, 2018.

Planta de la versión construida.

Fig. 08

Peter Zumthor, villa en Devon, 2018. Sala de estar en construcción.

Fig. 09

Peter Zumthor, villa en Devon, 2018. Foto Jack Hobhouse.

\section{Fig. 10}

Mies van der Rohe, prototipo de casa de $50 \times 50$ pies, 1950 . 
Fig. 11

Peter Zumthor, villa en Devon, 2018. Ala de dormitorios en construcción.

Fig. 12

Peter Zumthor, termas en Vals, 1996. Foto Nick Kane.

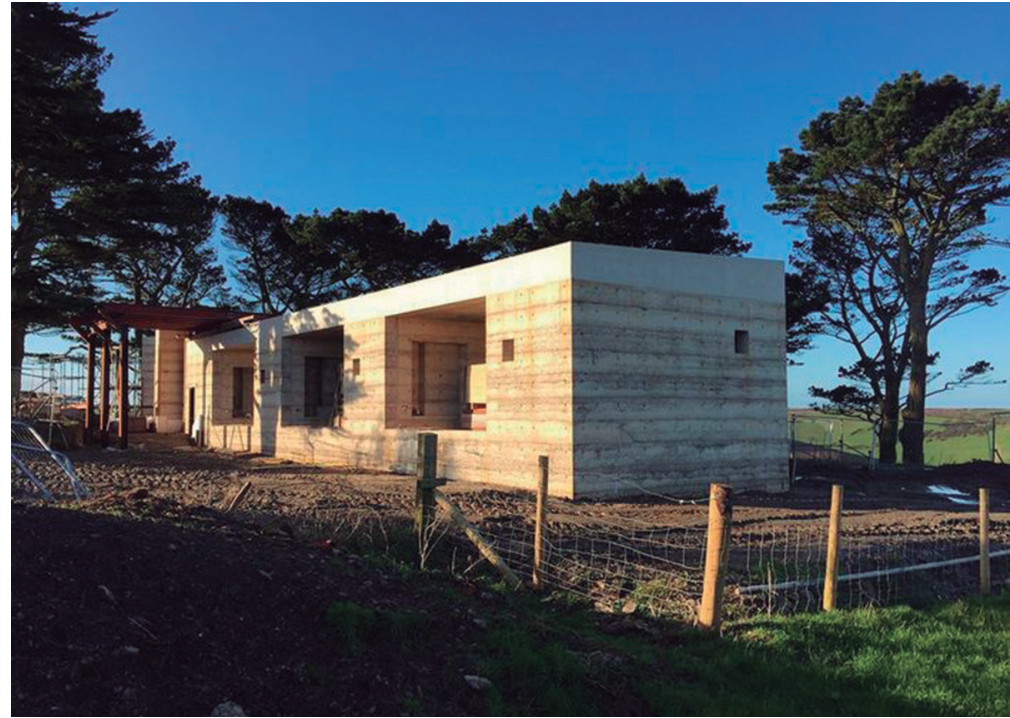

11

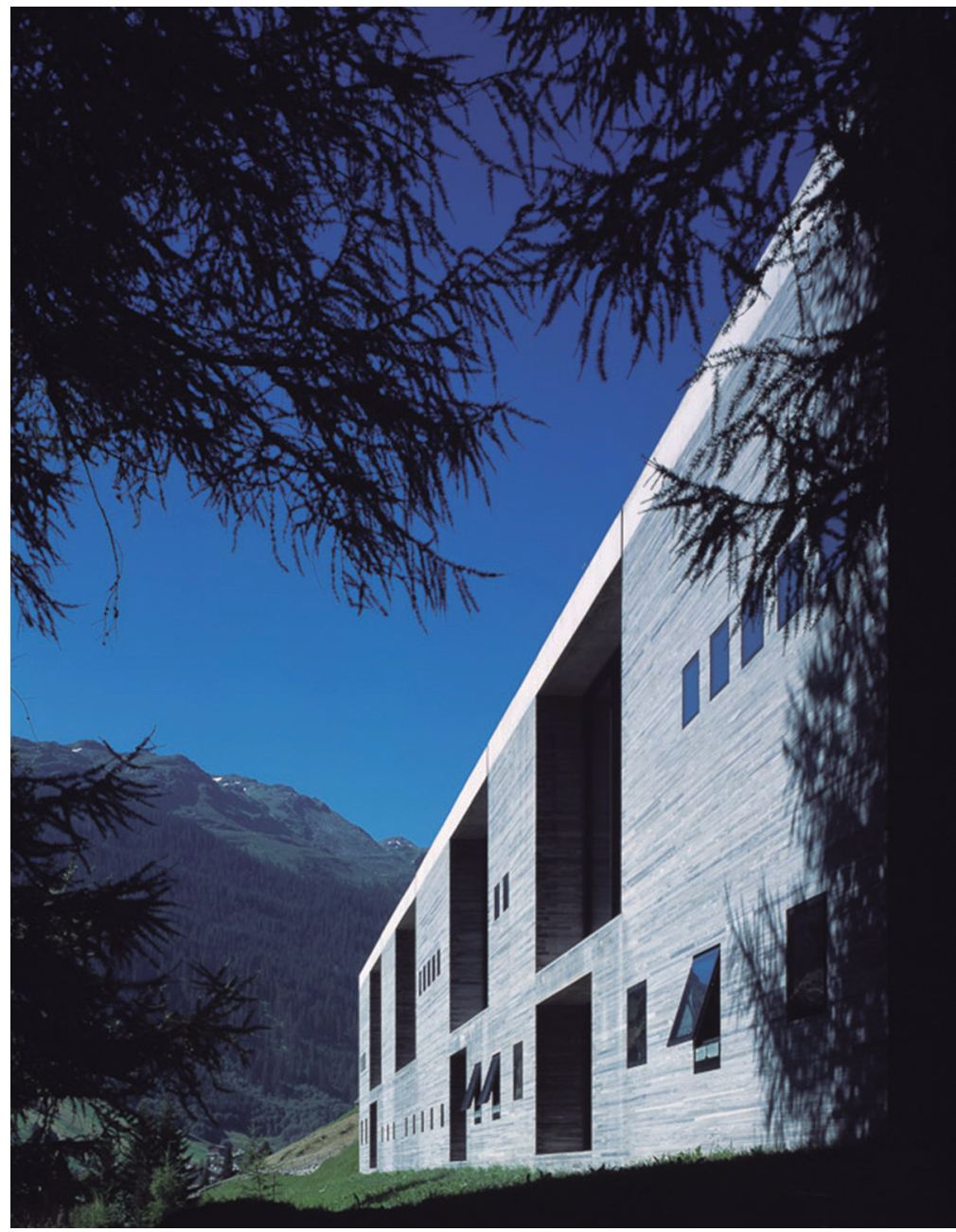


Las alusiones y relatos enumerados a propósito de las piezas en Londres y Devon no pretenden ser un inventario exhaustivo. No tendría sentido que lo fuera en un trabajo de esta extensión ni sería coherente con la realidad explicada. Otros podrán corregirlos o añadir incorporaciones valiosas, como también podrán incluir multitud de obras de arquitectura actuales resultado de otras tantas navegaciones. Pueden igualmente trazarse familias de proyectos relacionados por las fuentes de sus bitácoras particulares, las cuales se retroalimentan en corrientes que surcan los sitios de la World Wide Web más admirados por nuestra profesión.

NAVEGAR, AVISTAR Y USAR
El mecanismo no es el de una "civilización", como diría Michel Houellebecq, que "muere por cansancio"15. Los arquitectos navegantes pertenecen a un periodo decadente, sí -lo cual, por sí mismo, los convierte ya en objeto codiciado-, pero sobre todo son pioneros de una época que se abre paso. Es decir, no han perdido la capacidad de producción -la "originalidad" si usáramos el término popularmente aceptado- sino que han renunciado al proyecto entendido con el viejo significado de la exploración, todavía comúnmente utilizado en la mayoría de escuelas de arquitectura del mundo.

Nadie auguraría mucho éxito a una profesión de exploradores en un mundo ya tan sobreexplorado e hipertransitado como el nuestro -que incluso, por la misma existencia de esos tránsitos incesantes y machaconamente repetidos, ha debido durante la pandemia detener temporalmente todos sus movimientos en un acuerdo tácito sin precedentes-.

Estamos por el contrario ante la lógica utilización de un conocimiento que no parece tener fin, que sigue en crecimiento a una velocidad casi imposible de calcular y cuya consideración obliga a una forma diferente de trabajar y, también, de producir arquitectura, a una nueva "especiación". Podría identificarse como un fenómeno derivado de la revolución digital, incluso en el sentido que Paul Mason otorga a su "postcapitalismo", según el cual la disponibilidad del conocimiento a bajo precio abre las puertas, por la propia dificultad de su dosificación, a una era del "compartir" y a la consecuente "contradicción" en el poder anteriormente establecido ${ }^{16}$. "Compartir" convierte itodo! el volumen creciente de las piezas de arquitectura en un inabarcable capital circulante de uso acumulativo mientras los arquitectos habituados a la vieja "búsqueda" se enfrentan a una "contradicción" sistémica.

Resulta esclarecedor analizar la evolución de los términos -ojalá los metadatos se utilizaran más en la teoría de la arquitectura- "exploration" y "browsing" publicados durante las últimas décadas. Mientras el primero crece casi parabólicamente y alcanza su cima en 1980, cuando multiplica por 17 las apariciones del segundo, este remonta en ese momento y comienza a ganar las posiciones que aquel pierde durante el final del siglo $X X^{17}$. La navegación sin rumbo toma el relevo, como las "redes" lo hacen sobre las "jerarquías" en la teoría de Mason.

El proyecto, como la arquitectura, ha mutado en respuesta a la explosión de la conectividad, la profusión de la información y el aparente agotamiento de las ideas. Este mutado ejercicio proyectivo posee características casi idénticas, como hemos visto, en obras que bien podemos calificar de opuestas en cuanto a escala, ubicación, propósito 
y tipo de cliente, y en oficinas también opuestas por su vinculación con el exterior, es decir, por su radical diferencia en relación con las actuales fuerzas de producción, abiertamente directa una de ellas, velada por un entramado simbólico la otra.

Esta inversión del trabajo del proyecto demuestra una vez más que el uso de los datos es la tecnología que realmente transforma la disciplina, en oposición a los limitados avances de su propia fisicidad. A esta nueva tecnología la arquitectura se ha adherido de un modo automático. No ha necesitado meditarlo como hicieron los maestros del siglo pasado y hemos glosado al comienzo, tampoco establecerlo en una renovada Carta de Atenas o mucho menos decidirlo en convulsos congresos internacionales como los recurrentes CIAM. Se ha producido directamente, empujada a un abismo de conexiones por los viajes imparables del conocimiento en red.

La arquitectura ya no busca. Directamente encuentra, selecciona y aplica. Es más, si la navegación a través de lo existente significa ausencia de proyecto, es allí precisamente donde encuentra su ventaja para interpretar y desarrollar nuestro momento, en el cual, con palabras de Éric Vuillard, "la ausencia de proyecto es la forma contemporánea, posible y necesaria de la libertad"18. Vuillard no hablaba de arquitectura pero indudablemente podía haberlo hecho, no solo porque la producción suele preceder a los usos sociales, sino por la coincidencia de los "bloques de código" que identifica. Solo es posible la libertad sin proyecto, es necesario que sea así y es nuestro modo de conseguirla.

Efectivamente, la navegación anuncia un horizonte de libertad y de posibilidades, infinito y en constante crecimiento. La arquitectura del browsing no produce, por tanto, réditos hipotecados sino "hechos" -tomemos prestado el término de Le Corbusier como cabales navegantes digitales- libres, sensibles y audaces: el resultado desinteresado -recordemos, exento de predominio- de navegar, avistar y usar. RA 
01. SELVA, Caterina, "Landscapes of Coexistence", proyecto presentado a Future Architecture Platform, EU, 2018.

02. Congreso "Architecture of Coexistence", 3rd International Congress: Sustainability and Social Housing, Guadalajara, Mexico, 2018.

03. MULDER, Stephennie, "The Architecture of Coexistence: Sunnis, Shi'is, and the Shrines of the 'Alids in the Medieval Levant", University of Pennsylvania, 2008.

04. CAZZOLLA GATTI, Roberto, "A Conceptual Model of New Hypothesis on the Evolution of Biodiversity", Biological Diversity and Ecology Laboratory, BioClim-Land Centre of Excellence, Tomsk State University (TSU), Tomsk, Rusia, 2016.

05. MARQUES, D. A., LUCEK, K., MEIER, J. I., MWAIKO, S., WAGNER, C. E., EXCOFFIER, L., et al., "Genomics of Rapid Incipient Speciation in Sympatric Threespine Stickleback", 2016, PLoS Genet 12(2): e1005887. DOI: 10.1371/ journal. pgen.1005887.

06. OZENFANT, Amédée y JEANNERET, Charles-Edouard, "Recherches", L'Esprit Nouveau, núm. 22, París, 1924, p. 77.

07. Idem.

08. WRIGHT, Frank Lloyd, An Autobiography, Libro Cuarto (según la numeración de libros de 1943) "Freedom", 1930. En WRIGHT, Frank Lloyd, Autobiografía, El Croquis Editorial, Madrid, 1998, p. 438.

09. WRIGHT, Frank Lloyd, $A n$

Autobiography, Libro Quinto, "Form", 1943. En WRIGHT, Frank Lloyd, Autobiografía, EI Croquis Editorial, Madrid, 1998, p. 445.

10. Estudio Foster + Partners, fundado por Norman Foster en 1967. El equipo de proyecto dirigido por Norman Foster para el edificio Bloomberg estuvo compuesto también por Stefan Behling, Dan Sibert, Michael Jones, Annamaria Anderloni, Christopher Trott, Francis Aish, Irene Gallou, Kate Murphy, Mike Holland, Owe Schoof, Simona Bencini y Thouria Istephan. Fosteranpartners.com. Obtenido de https://www.fosterandpartners.com/ projects/bloomberg/ (22 junio 2021)
11. SELF, Jack, RUDENKO, Yulia, Mies in London, Real, Londres, 2017.

12. Atelier Peter Zumthor, fundado por Peter Zumthor en 1979. El equipo de proyecto dirigido por Peter Zumthor para la Villa en Debon estuvo compuesto también por Rainer Weitschies, Pascal Berchtold, Tom Tsapkov y Anna Page. Dezeen. com. Obtenido de https://www.dezeen. com/2018/10/29/peter-zumthor-secularretreat-living-architecture-villa-devon/ (22 junio 2021)

13. "Hormigón elemental, House by Peter Zumthor", Arquitectura Viva, núm. 210, Madrid, 2018, p. 12.

14. Coll-Barreu, Juan, Construcción de los paisajes inventados. Los Ángeles doméstico 1900-1960, Fundación Caja de Arquitectos, Barcelona, 2004, p. 61.

15. Cfr. Michel Houellebecq, Sérotonine, Flammarion, París, 2019.

16. Cfr. MASON, Paul, PostCapitalism: A Guide to Our Future, Penguin, Londres, 2015.

17. Metadatos por comparación dual de los libros publicados entre 1800 y la actualidad registrados por Google Books, 2020.

18. VUILLARD, Éric, "La revuelta del hombre corriente", El País, Madrid, ed. digital 10 Feb. 2019. 


\section{Bibliografía}

- CAZZOLLA GATTI, Roberto, "A Conceptual Model of New Hypothesis on the Evolution of Biodiversity", Biological Diversity and Ecology Laboratory, BioClim-Land Centre of Excellence, Tomsk State University (TSU), Tomsk, Rusia, 2016.

- COLL-BARREU, Juan, Construcción de los paisajes inventados. Los Ángeles doméstico 1900-1960, Fundación Caja de Arquitectos, Barcelona, 2004.

-Dezeen.com. https://www.dezeen. com/2018/10/29/peter-zumthor-secularretreat-living-architecture-villa-devon/ (22 junio 2021).

- FOSTER, Norman, «Willis Faber and Dumas Head Office», $A+U$, núm. 19885 extra edition, Tokyo, 1988.

- FOSTER, Norman, WRIGHT, Tom (ed.), BUCHANAN, Peter (text), Foster + Partners Portfolio 1967-2017, Foster + Partners, Londres, 2019.

- Fosteranpartners.com. https://www. fosterandpartners.com/projects/ bloomberg/ (22 junio 2021).

- GLANCEY, Jonathan, "Retablo urbano. Norman Foster, Bloomberg Offices (London)", Arquitectura Viva, núm. 208.10, Madrid, 2018.

- HOUELLEBECQ, Michel, Sérotonine, Flammarion, París, 2019.

- LUBETKIN, Berthold, ALLAN, John (ed.), Berthold Lubetkin: Architecture and the Tradition of Progress, Black Dog, 2013.

- MARQUES, D. A., LUCEK, K., MEIER, J. I., MWAIKO, S., WAGNER, C. E., EXCOFFIER, L., et al., "Genomics of Rapid Incipient Speciation in Sympatric Threespine Stickleback", PLoS Genet 12(2): e1005887. DOI: 10.1371/ journal.pgen.1005887, 2016.

- MASON, Paul, PostCapitalism: A Guide to Our Future, Penguin, Londres, 2015.

- MULDER, Stephennie, “The Architecture of Coexistence: Sunnis, Shi'is, and the Shrines of the "Alids in the Medieval Levant", University of Pennsylvania, 2008.

- OZENFANT, Amédée y JEANNERET, Charles-Edouard, “Recherches», L'Esprit Nouveau, núm. 22, París, 1924.
-SELF, Jack, RUDENKO, Yulia, Mies in London, Real, Londres, 2017.

- SELVA, Caterina, "Landscapes of Coexistence", proyecto presentado a Future Architecture Platform, EU, 2018.

- VUILLARD, Éric, "La revuelta del hombre corriente", El País, Madrid, ed. digital 10 Feb. 2019.

-WRIGHT, Frank Lloyd, Autobiografía, El Croquis Editorial, Madrid, 1998.

-ZUMTHOR, Peter et al., Peter Zumthor Therme Vals, Verlag Scheidegger Sr Spiess, Zurich, 20082 (2007).

- ZUMTHOR, Peter, «Hormigón elemental, House by Peter Zumthor», Arquitectura Viva, núm. 210, Madrid, 2018. 
